\title{
Feasibility and safety of rehabilitation after venous thromboembolism
}

This article was published in the following Dove Press journal:

Vascular Health and Risk Management

13 July 2015

Number of times this article has been viewed

\section{Frank Noack ${ }^{1,2}$ \\ Bernd Schmidt' \\ Mroawan Amoury 2 \\ Dietrich Stoevesandt ${ }^{3}$ \\ Stephan Gielen ${ }^{4}$ \\ Birgit Pflaumbaum ${ }^{5}$ \\ Christiane Girschick ${ }^{5}$ \\ Heinz Völler ${ }^{6}$ \\ Axel Schlitt ${ }^{5,7}$ \\ 'Department of Medicine I, \\ ${ }^{2}$ Department of Emergency Medicine, ${ }^{3}$ Department of Diagnostic Radiology, ${ }^{4}$ Department of Medicine III, University Clinic Halle (Saale), Halle, Germany; ${ }^{5}$ Department of Cardiology and Pulmology, Paracelsus-Harz- \\ Clinic Bad Suderode, Quedlinburg, Germany; ${ }^{6}$ Klinik am See, Rüdersdorf, Germany; ${ }^{7}$ Medical Faculty, Martin Luther University Halle, Wittenberg, Germany}

Correspondence: Axel Schlitt

Department of Cardiology and Pulmology, Paracelsus-Harz-Clinic Bad Suderode, 06485 Quedlinburg, Germany Tel +49394859 9900

Fax +49394 8599812

Email prof.dr.axel.schlitt@paracelsuskliniken.de
Background: Venous thromboembolism is a life-threatening disease. In survivors, different degrees of functional complaints need to be restored or prevented (eg, post-thrombotic syndrome, pulmonary hypertension). Therefore, rehabilitation after venous thromboembolism is recommended in Germany. However, a structured rehabilitation program has not been defined for this indication. Here, we present the experience of a single rehabilitation center.

Methods: Data from consecutive pulmonary embolism (PE) patients who were referred for a 3-week inpatient rehabilitation program from 2006 to 2014 were retrospectively evaluated.

Results: In all, 422 patients were identified. The mean age was $63.9 \pm 13.5$ years, the mean body mass index (BMI) was $30.6 \pm 6.2 \mathrm{~kg} / \mathrm{m}^{2}$, and $51.9 \%$ were female. Deep vein thrombosis according to PE was known for $55.5 \%$ of all patients. We applied a wide range of therapeutic interventions such as bicycle training with monitored heart rate in $86.7 \%$, respiratory training in $82.5 \%$, aquatic therapy/swimming in $40.1 \%$, and medical training therapy in $14.9 \%$ of all patients. Adverse events (AEs) occurred in 57 patients during the 3-week rehabilitation period. The most common AEs were cold $(n=6)$, diarrhea $(n=5)$, and infection of the upper or lower respiratory tract that was treated with antibiotics $(n=5)$. However, three patients under anticoagulation therapy suffered from bleeding, which was clinically relevant in one. Four patients $(0.9 \%)$ had to be transferred to a primary care hospital for non-PE-associated reasons (acute coronary syndrome, pharyngeal abscess, and acute abdominal problems). No influence of any of the physical activity interventions on the incidence of any AE was found.

Conclusion: Since PE is a life-threatening disease, it seems reasonable to recommend rehabilitation at least in PE patients with an intermediate or high risk. It is shown for the first time in this study that a standard rehabilitation program after PE is safe. However, efficacy and safety in the long term need to be studied prospectively.

Keywords: venous thromboembolism, pulmonary embolism, rehabilitation

\section{Introduction}

Pulmonary embolism (PE) represents a cardiovascular emergency and is one of the three most common causes of death from cardiovascular disease. One-year mortality after the target event is as high as $2.5 \%{ }^{1,2}$ Immediate and long-term anticoagulation therapy is indicated since, without anticoagulation, PE recurred within 3 months in approximately $50 \%$ of patients; however, clinically relevant and major bleedings occur in more than $8 \%$ of patients, especially in the initial phase of treatment. ${ }^{1-3}$ After initiating anticoagulation, immediate mobilization did not worsen outcome in patients with PE. ${ }^{4}$ Moreover, in low-risk patients early hospital discharge or even ambulatory treatment is recommended. ${ }^{5}$ Early walking exercise is safe in patients with acute 
deep vein thrombosis (DVT) and may help to reduce acute symptoms. Exercise training did not increase leg symptoms acutely in patients with a previous DVT and may help to prevent or improve the post-thrombotic syndrome. ${ }^{6}$ It seems reasonable to assume that $\mathrm{PE}$ patients with an intermediate or high risk will benefit from a rehabilitation program, which, at least in Germany, is already recommended. Here, the main objectives are to improve dyspnea and functional capacity in order to re-integrate patients into the work process. ${ }^{7}$

Some authors have reported the efficacy and safety of rehabilitation in patients with chronic thromboembolic pulmonary hypertension or other forms of pulmonary hypertension, ${ }^{8-10}$ but no studies have been published so far on rehabilitation after acute PE. Thus, in Germany, rehabilitation after $\mathrm{PE}$ has been adapted to that for patients with other severe cardiovascular and pulmonary diseases. Here, strong data exist that rehabilitation will not only improve guideline adherence to optimal medical therapy, sports therapy, and nutrition but also improve outcome. ${ }^{10-12}$ Such an inpatient rehabilitation includes a sports program consisting, for example, of bicycle training, power endurance workout, swimming, Nordic walking, an educational program regarding nutrition, medical therapy, pathophysiology, and medical treatment, and, last but not least, psychological and social support.

\section{Materials and methods}

To evaluate PE patient characteristics and safety of the rehabilitation process, data were analyzed from patients who underwent rehabilitation in the Paracelsus-Harz-Clinic Bad Suderode, Quedlinburg, Germany, from 2006 to 2014. Patients were retrospectively identified via the database of the clinic. The local ethics committee of the Medical Association of Saxony-Anhalt approved the study protocol.

Standard rehabilitation for patients with $\mathrm{PE}$ in the Paracelsus-Harz-Clinic consists of medical history and electrocardiogram (ECG) at admission and cycle ergometry (with blood gas analysis) and echocardiography the day after admission. For patients who were not able to perform cycle ergometry, a 6-minute walking test was alternatively conducted. Depending on physical fitness, severity of primary disease, comorbidities, and other confounders, the sports and rehabilitation program was set up the day after admission. Patients in good clinical condition participated every day (except Sunday) in heart rate-monitored 30-minute cycle ergometry training. Moreover, these patients participated in Nordic walking, medical training therapy, intensive gymnastics/exercise, and pulmonological functional exercise as aquatic therapy.
Patients who were less physically fit participated in group exercises, chair exercising, and walking exercises, and personal training sessions. All patients, independent of their physical fitness, received respiratory training and attended seminars and lectures as part of the 3-week rehabilitation program.

\section{Statistical methods}

Continuous variables are reported as mean \pm standard deviation (SD), skewed variables as median and interquartile range $25 / 75$, and categorical variables as percentage. Student's $t$-test, Mann-Whitney U-test, and chi-square test were used to compare continuous, skewed, and categorical variables, respectively. A $P$-value $<0.05$ was considered statistically significant. All computations were carried out with SPSS software (V22, SPSS Inc., Chicago, IL, USA).

\section{Results}

A total of 422 patients were identified. The mean age was $63.9 \pm 13.5$ years, $51.9 \%$ were female, and mean BMI was $30.6 \pm 6.2 \mathrm{~kg} / \mathrm{m}^{2}$. DVT according to PE was diagnosed in $55.5 \%$ of all patients. Heart rate at rest was $75.4 \pm 11.1 \mathrm{bpm}$ at admission. Mean systolic blood pressure $(135.3 \pm 19.1 \mathrm{mmHg})$ and mean diastolic blood pressure $(80.7 \pm 10.8 \mathrm{mmHg})$ were in the normal range; however, arterial hypertension was reported in $72.7 \%$ of all patients at admission. Other cardiovascular risk factors included active smoking in $6.2 \%$, dyslipoproteinemia in $60.2 \%$, and diabetes in $22.7 \%$. Further comorbidities are presented in Table 1. Length of stay at the rehabilitation clinic was $21.8 \pm 3.1$ days.

Table I Patient characteristics

\begin{tabular}{ll}
\hline Variable & $\mathbf{n = 4 2 2}$ \\
\hline Sociodemographic data & \\
Age (years) & $63.9 \pm 13.5$ \\
Female sex (\%) & 51.9 \\
BMI (kg/m²) & $30.6 \pm 6.2$ \\
Patient history & \\
Deep vein thrombosis related to PE (\%) & 55.5 \\
Active smoking (\%) & 6.2 \\
Hypertension (\%) & 72.7 \\
Diabetes (\%) & 22.7 \\
COPD (\%) & 13.0 \\
Renal insufficiency & 7.3 \\
Atrial fibrillation (\%) & 9.7 \\
Coronary heart disease (\%) & 9.5 \\
Vital parameters & \\
BP systolic (mmHg)* & $135.3 \pm 19.1$ \\
BP diastolic (mmHg)* & $80.7 \pm 10.8$ \\
Heart rate (bpm)* & $75.4 \pm 11.1$ \\
\hline
\end{tabular}

Notes: Categorical variables are presented in percent; continuous normally distributed variables as mean \pm standard deviation *at admission.

Abbreviations: BMI, body mass index; PE, pulmonary embolism; BP, blood pressure; bpm, beats per minute. 
Drug treatment is outlined in Table 2. As expected, all patients were on anticoagulation therapy both at admission and at discharge. According to bridging therapy, low-molecular-weight heparin was delivered less often and vitamin $\mathrm{K}$ antagonist was prescribed more often at discharge than at admission. Only a few patients were on therapy with new oral anticoagulants.

Since hypertension was a common diagnosis in this patient cohort, beta-blocking agents, angiotensin-convertingenzyme inhibitors, and angiotensin-receptor blockers were administered in the majority of patients (Table 2).

\section{Adverse events}

AEs occurred in 57 patients during rehabilitation. No indication-related complication was observed but four patients had to be re-hospitalized; all of them returned to the rehabilitation clinic for further treatment. One patient suffered from unstable angina, which was related to a newly diagnosed coronary heart disease and treated by a percutaneous intervention with stent implantation. One patient developed an abscess of the pharynx, which was surgically treated. Two patients suffered from severe abdominal pain, one related to subileus and the other to a severe urinary tract infection; both were treated conservatively. Bleedings occurred in three patients: two cases of epistaxis and one patient with anemia in whom occult blood in the stool was newly diagnosed. This patient rejected a direct referral for endoscopy, and therefore this was recommended in the discharge letter.

The most common AEs were common cold $(n=6)$, diarrhea $(n=5)$, and infection of the upper or lower respiratory tract that was treated with antibiotics $(n=5)$. AEs $(n \geq 3)$ are presented in Figure 1.

Table 2 Drug treatment at admission and discharge

\begin{tabular}{lll}
\hline Drug & Admission & Discharge \\
\hline LMWH (\%) & 16.1 & 3.8 \\
Oral anticoagulants & & \\
$\quad$ VKA (\%) & 79.4 & 85.8 \\
$\quad$ Rivaroxaban (\%) & 9.0 & 10.0 \\
$\quad$ Dabigatran (\%) & 0.5 & 0.5 \\
Aspirin (\%) & 7.6 & 4.3 \\
Beta-blockers (\%) & 51.7 & 59.5 \\
ACE-inhibitors (\%) & 35.8 & 37.0 \\
ARBs (\%) & 26.1 & 28.9 \\
Statins (\%) & 21.8 & 44.1 \\
Insulin (\%) & 8.8 & 8.5 \\
Antidiabetics (\%) & 8.3 & 8.8 \\
Antidepressives (\%) & 7.3 & 7.3 \\
\hline
\end{tabular}

Abbreviations: $\mathrm{LMWH}$, low-molecular-weight heparin; VKA, vitamin $\mathrm{K}$ antagonist $\mathrm{ACE}$, angiotensin-converting-enzyme; $\mathrm{ARB}$, angiotensin-receptor blocker.
Since risks and benefits of physical activity after PE were not well known, we further analyzed AEs during the patients' stay at the rehabilitation clinic in relation to the therapeutic interventions which were performed. A wide range of therapeutic physical activity was applied, such as bicycle training with monitored heart rate in $86.7 \%$, respiratory therapy in $82.5 \%$, aquatic therapy/swimming in $40.1 \%$, and medical training therapy in $14.9 \%$ of all patients (Table 3 ). Interestingly, patients without AEs participated in Nordic walking $(30.7 \%$ in patients without AEs vs $10.5 \%$ in patients with AEs during the rehabilitation, $P=0.002$ ) and in the group gymnastics (12.3\% in patients without AEs vs $3.5 \%$ in patients with AEs during the rehabilitation, $P=0.049$, Table 3 ) more often. On the other hand, patients with AEs participated significantly more often in chair exercises $(37.5 \%$ in patients without AEs vs $56.1 \%$ in patients with AEs, $P=0.008$ ) and walking exercises $(6.6 \%$ in patients without AEs vs $17.5 \%$ in patients with AEs, $P=0.005)$. Both are possibly related to other risk factors, ie, increased age in patients with AEs during the rehabilitation $(63.9 \pm 13.5$ years in patients without AEs vs $67.6 \pm 12.1$ years in patients with AEs, $P=0.024)$. No influence on the occurrence of AEs related to participating in aquatic therapy or swimming was found (Table 3).

To investigate the impact of age on AEs, patients with or without AEs were divided into different groups according to age. Here, a nonsignificant trend $(P=0.105$ by chi-square test) for a higher prevalence of AEs was found in patients at higher age. The incidence of AEs increased from $6 \%$ in patients under 50 years $(n=79)$ to $13.5 \%$ in patients above 50 and below 65 years $(n=104)$, and to $14.4 \%$ in patients with an age above 65 and below 75 years $(n=167)$. The highest incidence was found in the group of 71 patients who were older than 75 years $(19.7 \%)$.

\section{Discussion}

The main findings of this analysis, which to date comprises the first dataset for patients with the diagnosis of PE participating in an inpatient rehabilitation program, were: 1) incidence of serious AEs that complicated the rehabilitation process were rare and recurrent venous thromboembolism (VTE), severe bleedings, or deaths were not found; and 2) the suggested standard rehabilitation program including intensive sports therapy was safe.

German, ${ }^{13}$ European, ${ }^{1}$ and US ${ }^{14,15}$ guidelines on VTE have no provisions concerning rehabilitation after DVT or PE. However, according to the medical requirements for rehabilitation issued by the federal pension funding agency in Germany according to the German Social Code Book 


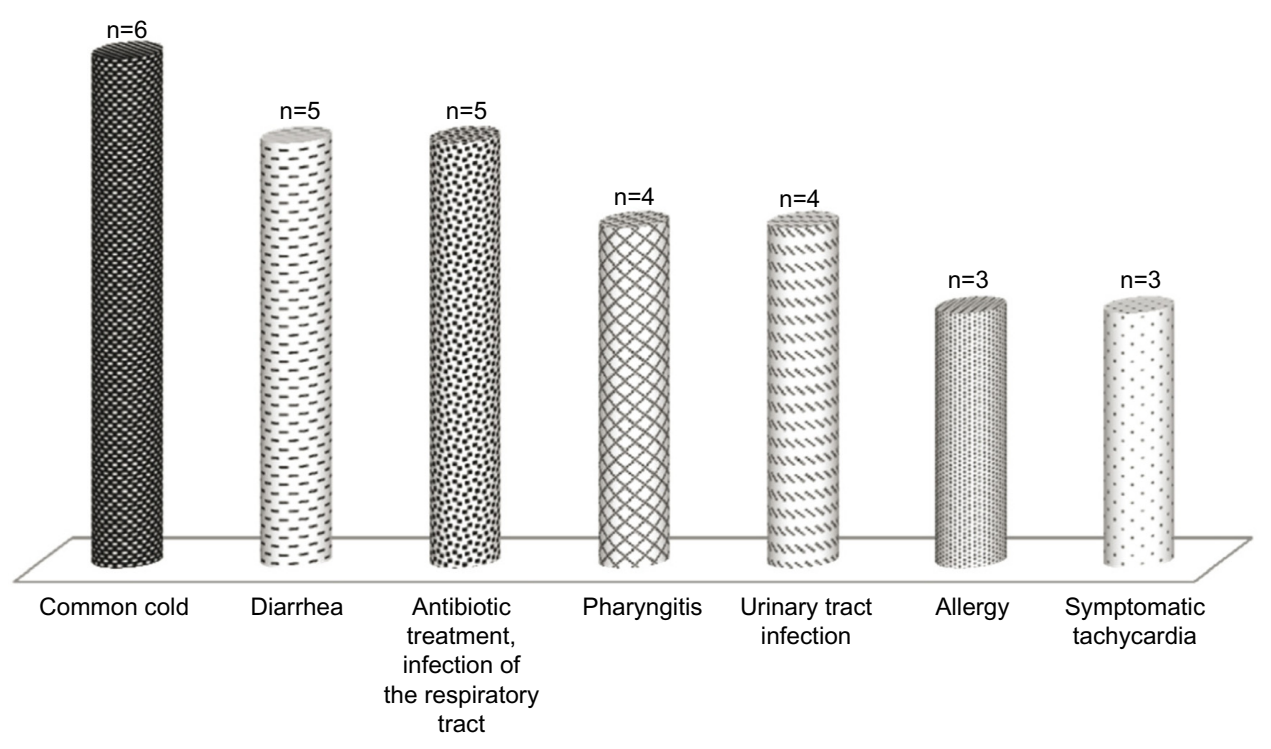

Figure I Adverse events.

(Sozialgesetzbuch IX = SGB IX), rehabilitation is recommended for patients with moderate to severe PE although data in support of this recommendation do not exist.

It seems reasonable according to published data to optimize treatment of patients with moderate to severe PE and include rehabilitation since VTE represents a significant risk for morbidity and mortality. ${ }^{14}$ In the German MAPPET (Management Strategy and Prognosis of Pulmonary Embolism) Registry of more than 1,000 patients with acute PE, in-hospital mortality was $8.1 \%$ for stable patients, $25 \%$ for patients with cardiogenic shock, and $65 \%$ for patients after cardiopulmonary resuscitation. Moreover, major bleeding was found in $9.2 \%$ and PE recurred in $17 \% .^{16}$

Table 3 Therapeutic interventions and adverse events

\begin{tabular}{lllll}
\hline Variable & All & No AEs & AEs & P-value \\
\hline $\begin{array}{l}\text { Bicycle training with monitored } \\
\text { heart rate (\%) }\end{array}$ & 86.7 & 88.2 & 77.2 & 0.220 \\
Medical training therapy (\%) & 14.9 & 15.6 & 10.5 & 0.316 \\
Group exercising (\%) & 60.7 & 61.4 & 56.1 & 0.452 \\
Chair exercises (\%) & 40 & 37.5 & 56.1 & 0.008 \\
Group gymnastics (\%) & 11.1 & 12.3 & 3.5 & 0.049 \\
Group aquatic therapy (\%) & 28.7 & 29 & 26.3 & 0.672 \\
Pulmonological functional exercise (\%) & 14.9 & 15.6 & 10.5 & 0.316 \\
Pulmonological functional exercise & 9 & 9.3 & 7 & 0.573 \\
as aquatic therapy (\%) & & & & \\
Walking exercise (\%) & 8.1 & 6.6 & 17.5 & 0.005 \\
Respiratory therapy/training (\%) & 82.5 & 81.9 & 86 & 0.455 \\
Nordic walking (\%) & 28 & 30.7 & 10.5 & 0.002 \\
Reflective respiratory therapy (\%) & 10.4 & 9.3 & 17.5 & 0.059 \\
Swimming (\%) & 40.8 & 41.6 & 35.1 & 0.349 \\
\hline Abbrim
\end{tabular}

Abbreviation: AEs, adverse events.
Since early mobilization is safe after $\mathrm{PE},{ }^{4}$ ambulatory treatment of PE in low-risk patients is possible, ${ }^{5}$ and patients with other cardiovascular diseases profit from mobilization and sports therapy after the index event. ${ }^{11,12}$ Early physical activity including well-dosed and monitored sports therapy seems to be a reasonable treatment in patients after PE. This hypothesis can be confirmed in the present analysis of consecutive patients with PE in a German rehabilitation clinic. Patients in good condition participated in an intensive sports program including once-daily heart rate-monitored cycle ergometric training, Nordic walking, medical training therapy, aquatic therapies, and swimming. Patients in poorer general condition also participated in a less-intensive physical exercise program. These programs were well tolerated and safe since no serious AEs related to the basic disease PE such as recurrent DVT/PE or severe bleedings developed and no patient died during the 3-week rehabilitation program.

Another finding of this study is the low incidence of bleeding complications. In the first 2 weeks after the index event, patients were admitted to the rehabilitation program, which lasted for $21.8 \pm 3.1$ days (Table 1 ). In this period only two minor bleedings and one clinically relevant bleeding (see Results section) were found, which means a low bleeding incidence of approximately $0.7 \%$. In the Einstein PE study on the efficacy and safety of rivaroxaban in comparison to warfarin, clinically relevant bleedings in the first 30 days after the index event were as high as approximately $5 \%$ in both study arms. ${ }^{17}$ Thus, we hypothesize that the rehabilitation process provides another safety measure for patients after $\mathrm{PE}$ as shown in this analysis. 


\section{Limitations}

The study is limited by its retrospective and monocentric nature, which has the potential for under-reporting (eg, bleeding events) as compared with prospective clinical trials and which may explain the small number of bleeding events reported in this study. Other limitations were the lack of a control group and the missing comparison of baseline data versus rehabilitation data.

\section{Conclusion}

Although limited by its retrospective and monocentric design, this observational study showed that rehabilitation programs, which are recommended by the German federal pension funding agency for patients after PE, are safe. However, the long-term safety and, moreover, efficacy need to be evaluated in a prospective study. (clinicaltrials.gov. Identifier: NCT02002351).

\section{Acknowledgments}

We thank the study coordinator Viktoria Heinze for her input in data management and Mroawan Amoury for working on his thesis as a part of this study.

\section{Disclosure}

The authors report no conflicts of interest in this work.

\section{References}

1. Torbicki A, Perrier A, Konstantinides S, et al. ESC Committee for Practice Guidelines (CPG). Guidelines on the diagnosis and management of acute pulmonary embolism: the Task Force for the Diagnosis and Management of Acute Pulmonary Embolism of the European Society of Cardiology (ESC). Eur Heart J. 2008;29(18):2276-2315.

2. Goldhaber SZ, Bounameaux H. Pulmonary embolism and deep vein thrombosis. Lancet. 2012;379(9828):1835-1846.

3. Fontana P, Goldhaber SZ, Bounameaux H. Direct oral anticoagulants in the treatment and long-term prevention of venous thrombo-embolism. Eur Heart J. 2014;35(28):1836-1843.

4. Aissaoui N, Martins E, Mouly S, et al. A meta-analysis of bed rest versus early ambulation in the management of pulmonary embolism, deep vein thrombosis, or both. Int J Cardiol. 2009;137(1):37-41.

5. Konstantinides S, Torbicki A, Agnelli G, et al. 2014 ESC Guidelines on the diagnosis and management of acute pulmonary embolism: The Task Force for the Diagnosis and Management of Acute Pulmonary Embolism of the European Society of Cardiology (ESC) Endorsed by the European Respiratory Society (ERS). Eur Heart J. 2014;35(43):3033-3069.
6. Kahn SR, Shrier I, Kearon C. Physical activity in patients with deep venous thrombosis: a systematic review. Thromb Res. 2008; 122: $763-773$.

7. Kahn SR, Shrier I, Kearon C. Physical activity in patients with deep venous thrombosis: a systematic review. Thromb Res. 2008;122(6): 763-773.

8. Held M, Grün M, Holl R, et al. Cardiopulmonary exercise testing to detect chronic thromboembolic pulmonary hypertension in patients with normal echocardiography. Respiration. 2014;87(5):379-387.

9. Grünig E, Lichtblau M, Ehlken N, et al. Safety and efficacy of exercise training in various forms of pulmonary hypertension. Eur Respir $J$. 2012;40(1):84-92.

10. Mereles D, Ehlken N, Kreuscher S, et al. Exercise and respiratory training improve exercise capacity and quality of life in patients with severe chronic pulmonary hypertension. Circulation. 2006;114(14): $1482-1489$.

11. Heran BS, Chen JM, Ebrahim S, et al. Exercise-based cardiac rehabilitation for coronary heart disease. Cochrane Database Syst Rev 2011;(7):CD001800.

12. Steg PG, James SK, Atar D, et al. Task Force on the management of ST-segment elevation acute myocardial infarction of the European Society of Cardiology (ESC). ESC Guidelines for the management of acute myocardial infarction in patients presenting with ST-segment elevation. Eur Heart J. 2012;33(20):2569-2619.

13. Hach-Wunderle V. Arbeitsgemeinschaft der Wissenschaftlichen Medizinischen Fachgesellschaften: [Interdisciplinary S2-Guideline diagnosis and treatment of deep vein thrombosis and pulmonary embolism]. AWMF online - S2-Leitlinie Angiologie: Venenthrombose und Lungenembolie. VASA 2010; 39: S/78 AWMF Reg-Nr. 065/002 German. Available from: http://www.awmf.org/leitlinien/detail/11/065002.html.

14. Jaff MR, McMurtry MS, Archer SL, et al. American Heart Association Council on Cardiopulmonary, Critical Care, Perioperative and Resuscitation; American Heart Association Council on Peripheral Vascular Disease; American Heart Association Council on Arteriosclerosis, Thrombosis and Vascular Biology. Management of massive and submassive pulmonary embolism, iliofemoral deep vein thrombosis, and chronic thromboembolic pulmonary hypertension: a scientific statement from the American Heart Association. Circulation. 2011;123(16):1788-1830.

15. Kearon C, Akl EA, Comerota AJ, et al. American College of Chest Physicians. Antithrombotic therapy for VTE disease: Antithrombotic Therapy and Prevention of Thrombosis, 9th ed.: American College of Chest Physicians Evidence-Based Clinical Practice Guidelines. Chest. 2012;141(Suppl 2):e419S-e494S.

16. Kasper W, Konstantinides S, Geibel A, et al. Management strategies and determinants of outcome in acute major pulmonary embolism: results of a multicenter registry. J Am Coll Cardiol. 1997;30(5): $1165-1171$

17. EINSTEIN-PE Investigators, Büller HR, Prins MH, Lensin AW, et al. Oral rivaroxaban for the treatment of symptomatic pulmonary embolism. N Engl J Med. 2012;366(14):1287-1297.
Vascular Health and Risk Management

\section{Publish your work in this journal}

Vascular Health and Risk Management is an international, peerreviewed journal of therapeutics and risk management, focusing on concise rapid reporting of clinical studies on the processes involved in the maintenance of vascular health; the monitoring, prevention and treatment of vascular disease and its sequelae; and the involvement of

\section{Dovepress}

metabolic disorders, particularly diabetes. This journal is indexed on PubMed Central and MedLine. The manuscript management system is completely online and includes a very quick and fair peer-review system, which is all easy to use. Visit http://www.dovepress.com/ testimonials.php to read real quotes from published authors. 